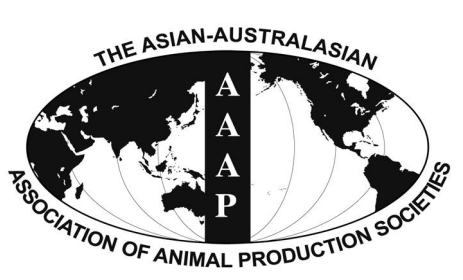

Open Access

Asian Australas. J. Anim. Sci.

Vol. 29, No. 11 : 1547-1554 November 2016

http://dx.doi.org/10.5713/ajas.15.1060

www.ajas.info

pISSN 1011-2367 elSSN 1976-5517

\title{
Maternal Origin of Turkish and Iranian Native Chickens Inferred from Mitochondrial DNA D-loop Sequences
}

\author{
Hasan Meydan*, Cafer Pish Jang ${ }^{1}$, Mehmet Ali Yıldız ${ }^{2}$, and Steffen Weigend ${ }^{3}$ \\ Department of Agricultural Biotechnology, Faculty of Agriculture, Akdeniz University, Antalya 07058, Turkey
}

\begin{abstract}
To assess genetic diversity and maternal origin of Turkish and Iranian native chicken breeds, we analyzed the mtDNA D-loop sequences of 222 chickens from 2 Turkish (Denizli and Gerze) and 7 Iranian (White Marandi, Black Marandi, Naked Neck, Common Breed, Lari, West Azarbaijan, and New Hampshire) native chicken breeds, together with the available reference sequences of G. gallus gallus in GenBank. The haplotype diversity was estimated as $0.24 \pm 0.01$ and $0.36 \pm 0.02$ for Turkish and Iranian populations, respectively. In total, 19 haplotypes were observed from 24 polymorphic sites in Turkish and Iranian native chicken populations. Two different clades or haplogroups (A and E) were found in Turkish and Iranian chickens. Clade A haplotypes were found only in White Marandi, Common Breed and New Hampshire populations. Clade E haplotypes, which are quite common, were observed in Turkish and Iranian populations with 18 different haplotypes, of which Turkish and Iranian chickens, Clade E, haplotype 1 (TRIRE1) was a major haplotype with the frequency of $81.5 \%$ (181/222) across all breeds. Compared to red jungle fowl, Turkish and Iranian chicken breeds are closely related to each other. These results suggest that Turkish and Iranian chickens originated from the same region, the Indian subcontinent. Our results will provide reliable basic information for mtDNA haplotypes of Turkish and Iranian chickens and for studying the origin of domestic chickens. (Key Words: Turkish Native Chicken Breeds, Iranian Native Chicken Breeds, mtDNA D-loop, Haplogroup, Maternal Origin)
\end{abstract}

\section{INTRODUCTION}

The domestic chicken is among the most popular and widespread domestic animal species. For thousands of years, chickens have been used as source of food, for religious activities, decorative arts, and entertainment (Liu et al., 2006). Chickens were probably domesticated from the red jungle fowl (Gallus gallus), as early as 5400 BC according to archaeological discoveries in the Indus Valley and in Hebei Province, China (West and Zhou, 1989; Crawford, 1995). There are different hypotheses about chicken

\footnotetext{
* Corresponding Author: Hasan Meydan. Tel: +90-506-662-7165, Fax: +90-242-227-4564, E-mail: meydan@akdeniz.edu.tr

${ }^{1}$ Department of Animal Science, Islamic Azad University of Maragheh, Maragheh 11369, Iran.

${ }^{2}$ Department of Animal Science, Faculty of Agriculture, Ankara University, Ankara 06100, Turkey.

${ }^{3}$ Friedrich-Loeffler-Institut, Institute of Farm Animal Genetics, Mariensee, Neustadt D-31535, Germany.

Submitted Dec. 24, 2015; Revised Apr. 1, 2016; Accepted May 10, 2016
}

domestication in literature. Based on molecular data, Eriksson et al. (2008) have suggested an introgression of Gallus sonneratii into modern chicken breeds. In contrast, Fumihito et al. (1994; 1996) argued that domestic chickens have a monophyletic origin from Gallus gallus gallus, and all the domestic breeds might have originated from a single domestication event that occurred in Thailand and adjacent regions. Kanginakudru et al. (2008) found evidence for domestication of Indian chickens from Gallus gallus spadiceus, Gallus gallus gallus, and Gallus gallus murghi.

In spite of their low production level, native chicken breeds may be well suited to be raised under village conditions due to their adaptation to local conditions (Besbes, 2009). They are, therefore, considered as invaluable genetic resources. Such local breeds are to be conserved to maintain genetic diversity as basic material for future breeding programs to adapt populations to unforeseen requirements as well as a source of research material (Romanov and Weigend, 2001). Nevertheless, native chickens are facing extinction because of their poor 
commercial performance. For conservation and improvement, native chicken populations need to be defined at molecular level.

Mitochondrial DNA (mtDNA) sequence polymorphisms have frequently been used in different species to assess maternal lineages. In chickens, Liu et al. (2006) revealed nine highly divergent mtDNA clades (named clades A-I) by analyzing the mtDNA hypervariable segment I and assumed multiple and independent domestication events in South China, Southeast Asia and the Indian subcontinent. Oka et al. (2007) also identified seven clades (named clades A-G) in Japanese chickens.

The Denizli and Gerze breeds are two of the Turkish native chickens (Bilgemre, 1939; Düzgüneş, 1990). These breeds are registered in "Breeds Currently Recorded in the Global Databank for Animal Genetic Resources" by FAO. Denizli and Gerze breeds are primarily reared for hobby and eggs in the province of Denizli and Sinop, respectively. Denizli cocks are famous for their long crowing (app. 10 to $25 \mathrm{~s}$ ). In spite of the national program of genetic preservation of native chickens titled "The Conservation of Turkish Native Chickens, Denizli and Gerze" since 1997, these breeds are still in serious danger of extinction. Iran has a long history of poultry husbandry. It can be traced back to the times of ancient Persia, when the chicken was apparently introduced to that country by the Aryan people from the Indus Valley civilization (present-day Pakistan) around 2500 through 2000 BC (Crawford, 1995; Shariatmadari, 2000; Shahbazi et al., 2007). White Marandi, Black Marandi, Naked Neck, Common Breed, Lari, and West Azarbaijan are the Iranian native chickens. In addition, chickens of New Hampshire breed were also included in this study for comparison, though they are not indigenous to Iran. These native chicken populations are kept at research centers and were originally found in villages and rural areas. To the best of our knowledge, there is only one published study (Kaya and Yildiz, 2008) which characterizes the genetic diversity of Turkish native chicken populations, Denizli and Gerze, at molecular level using microsatellite markers. There is a wider literature focusing on RAPD
(Rahimi et al., 2002; Mirhosseini and Dehghanzadeh, 2003) or microsatellite markers (Shahbazi et al., 2007) to characterize the genetic diversity of Iranian chicken populations. In spite of these studies on these chicken breeds, mtDNA provides better insight into possible maternal origins of Turkish and Iranian chicken breeds which have not been assessed previously.

The aim of this study was to analyze the mtDNA D-loop region of two Turkish and seven Iranian chicken populations to determine mtDNA haplotypes, to clarify their phylogenetic relationship and haplogroups, and to assess their possible maternal origin by comparing the haplotypes found in this study with previous studies.

\section{MATERIALS AND METHODS}

\section{Sampling and DNA isolation}

In this study, a total of 222 chickens were sampled from Turkish and Iranian native chicken breeds. Two Turkish (Denizli and Derze) and seven Iranian (White Marandi, Black Marandi, Naked Neck, Common Breed, Lari, New Hampshire, and West Azarbaijan) chicken breeds were included for this study (Table 1). Blood samples were collected from the wing vein with sterile syringes into a tube containing ethylenediaminetetraacetic acid, transported to laboratory and stored at $-20^{\circ} \mathrm{C}$ until genomic DNA extraction, which was carried out using salting-out method according to Miller et al. (1988). The sampling and handling of the chickens were approved by the Animal Experimentations Local Ethics Board at Ankara University.

\section{mtDNA D-loop amplification and sequencing}

The fragment of $465 \mathrm{bp}$ in length from the D-loop region of the chicken mtDNA was amplified by polymerase chain reaction (PCR). The amplification reactions were prepared in a final volume of $20 \mu \mathrm{L}$ containing as follows: 1 $\times$ PCR buffer, $0.2 \mathrm{mM}$ dNTPs, 0.5 U Taq DNA Polymerase, $1.5 \mathrm{mM} \mathrm{MgCl}_{2}, 10 \mathrm{pM}$ of forward (5' GGC TTG AAA AGC CAT TGT TG 3') and reverse (5' CCC CAA AAA GAG AAG GAA CC 3') primers suggested by Muchadeyi

Table 1. Country, breed, abbreviation, sampling location and sample size (n) of chickens used in this study

\begin{tabular}{|c|c|c|c|c|}
\hline Country & Breed & Abbreviation & Sampling location & $\mathrm{n}$ \\
\hline \multirow[t]{3}{*}{ Turkey } & Denizli & TRD & Lalahan Livestock Central Animal Research Institute & 16 \\
\hline & & & Denizli Cock Rearing Farm & 15 \\
\hline & Gerze & TRG & Lalahan Livestock Central Animal Research Institute & 23 \\
\hline \multirow[t]{7}{*}{ Iran } & White Marandi & IRWM & Kerec Research Institute & 23 \\
\hline & Black Marandi & IRBM & Kerec Research Institute & 30 \\
\hline & Naked Neck & IRNN & Kerec Research Institute & 22 \\
\hline & Common Breed & IRCB & Kerec Research Institute & 23 \\
\hline & New Hampshire & IRNH & Kerec Research Institute & 23 \\
\hline & Lari & IRLR & East Azerbaijan Rearing Central & 24 \\
\hline & West Azerbaijan & IRWA & Urmia Research Institute & 23 \\
\hline
\end{tabular}


et al. (2008), and $100 \mathrm{ng}$ DNA. Amplification was performed using an initial denaturation of $5 \mathrm{~min}$ at $94^{\circ} \mathrm{C}$, followed by 35 cycles of $1 \mathrm{~min}$ at $95^{\circ} \mathrm{C}, 1 \mathrm{~min}$ at $57^{\circ} \mathrm{C}$, and $1 \mathrm{~min}$ at $72^{\circ} \mathrm{C}$, and a final extension step of $5 \mathrm{~min}$ at $72^{\circ} \mathrm{C}$. PCR products were controlled by electrophoresis on $2 \%$ agarose gels. After gel electrophoresis, the amplicons were purified using a Qiamp Mini Kit (QIAGEN, Valencia, CA, USA). The purified samples were sequenced using a Big dye terminator chemistry on an ABI 3100 Avant Automated DNA Sequencer (Applied Biosystems, Foster City, CA, USA). The DNA sequences were analyzed by the Sequencing Analysis Software Version 3.3 (Applied Biosystems, USA).

\section{Data analysis}

The sequences of $465 \mathrm{bp}$ in length from mtDNA D-loop region were aligned with MEGA 4.1 software (Kumar et al., 2008). The position and number of polymorphic sites as well as corresponding haplotypes were calculated using DNASP software (Librado and Rozas, 2009). We used ARLEQUIN software (Excoffier et al., 2005) to calculate haplotype diversity $(\mathrm{h})$, nucleotide diversity $(\pi)$, and analysis of molecular variance. We constructed an unrooted neighbor-joining (NJ) tree of breeds under study including red jungle fowl (G. g. gallus, AB007720; AP003322) using Splits Tree4 software (Huson and Bryant, 2006). In order to determine the relationships of haplotypes, and obtain haplogroup information, median joining networks were constructed using the NETWORK 4.1 software (http://www.fluxus-engineering.com/sharenet.htm). Several GenBank sequences of previous studies were used for these analyses (Table 2).

Table 2. Haplotype names and GenBank accession numbers of chicken mtDNA sequences used in this study

\begin{tabular}{lll}
\hline Haplotype & \multicolumn{1}{c}{ Accession no. } & \multicolumn{1}{c}{ Reference } \\
\hline TRIRE1 & KT596789 & This study \\
TRE2-TRE4 & KT596790- KT596792 & This study \\
IRE5 & KT596793 & This study \\
IRA & KT596794 & This study \\
IRE6-IRE18 & KT596795- KT596807 & This study \\
Liu_A1 & AB114069 & Liu et al., 2006 \\
Liu_B1 & AB007744 & Liu et al., 2006 \\
Liu_C1 & AB114070 & Liu et al., 2006 \\
Liu_D1 & AY588636 & Liu et al., 2006 \\
Liu_E1 & AB114076 & Liu et al., 2006 \\
Liu_F1 & AF512285 & Liu et al., 2006 \\
Liu_G1 & AF512288 & Liu et al., 2006 \\
Liu_H1 & D82904 & Liu et al., 2006 \\
Liu_I1 & AB009434 & Liu et al., 2006 \\
RJF1 & AB007720 & Miyake, 1997 \\
RJF2 & AP003322 & Nishibori et al., 2005 \\
\hline
\end{tabular}

\section{RESULTS}

\section{Sequence variation and haplotype distribution}

In total, 19 haplotypes were observed from 24 polymorphic sites for 222 chickens from Turkish and Iranian native breeds (Figure 1). All polymorphic sites were due to substitution mutations, all of which were transitions. For this study, the individual haplotypes were abbreviated TR (Turkish) or IR (Iranian) A/E followed by a number. Two different clades $\mathrm{A}$ and $\mathrm{E}$ were named according to the nomenclature suggested by Liu et al. (2006). In this study, they were formed by 19 haplotypes, of which 3 (Turkish chickens, Clade E, haplotype 2 [TRE2], TRE3, and TRE4) were only found in Turkish native chickens, 15 haplotypes were only found in Iranian native chickens, and the one haplotype, Turkish and Iranian chickens, Clade E, haplotype 1 (TRIRE1), was in common. The nucleotide sequences of all haplotypes were deposited in GenBank with the accession number of KT596789-KT596807.

Clade A was found in three chickens from Iranian chicken population (White Marandi, New Hampshire, and Common Breed) under this study. All three chickens shared same haplotype, Iranian chickens, Clade A (IRA). Clade E was subdivided into 18 different haplotypes (Table 3). Among these 18 haplotypes, only one haplotype (TRIRE1) was shared between Turkish $(n=47)$ and Iranian $(n=134)$ chicken populations with the frequency of $81.5 \%$ overall

\begin{tabular}{|c|c|c|c|}
\hline & $\begin{array}{r}671122222222222233333334 \\
786911224444568911134594 \\
7927252369612914613627\end{array}$ & $\mathrm{~N}$ & $\begin{array}{l}\text { GenBank } \\
\text { Accession } \\
\text { Number }\end{array}$ \\
\hline TRIRE1 & ССTTGCACGCCACTACTCCСАTCT & 181 & KT596789 \\
\hline TRE2 & $\ldots \subset \ldots \ldots \ldots \ldots \ldots \ldots$ & 5 & KT596790 \\
\hline TRE3 & TT $\ldots \ldots \ldots \ldots \ldots \ldots$ & 1 & KT596791 \\
\hline TRE4 & $. T . C \ldots \ldots \ldots \ldots \ldots \ldots$ & 1 & KT596792 \\
\hline IRE5 & $\ldots \ldots \ldots \ldots \ldots \ldots \ldots \ldots$ & 7 & KT596793 \\
\hline IRA & $\ldots$ C.T.T.T.TC . С.... & 3 & KT596794 \\
\hline IRE 6 & $\ldots \ldots$ A $\ldots$ A $\ldots \ldots$. & 1 & KT596795 \\
\hline IRE7 & $\ldots \ldots$ A $\ldots$ A . A G & 3 & KT596796 \\
\hline IRE8 & $\ldots \ldots$ G. $\ldots$. . . & 3 & KT596797 \\
\hline IRE9 & $\ldots \ldots \ldots$. & 1 & KT596798 \\
\hline IRE10 & $\ldots \ldots \ldots \ldots \ldots \ldots \ldots$ & 1 & KT596799 \\
\hline IRE11 & $\ldots \ldots \ldots \ldots \ldots \ldots \ldots$ & 4 & KT596800 \\
\hline IRE12 & ...G...G.C....... & 1 & KT596801 \\
\hline IRE13 & ...G...G.C......... & 1 & KT596802 \\
\hline IRE14 & $\ldots \ldots \ldots \ldots \ldots$ & 1 & KT596803 \\
\hline IRE15 & 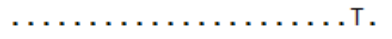 & 5 & KT596804 \\
\hline IRE16 & $\ldots$. АТ ... Т.TC..С.Т... & 1 & KT596805 \\
\hline IRE17 & $\ldots \ldots \ldots \ldots \ldots$ & 1 & КT596806 \\
\hline IRE18 & $\ldots \ldots$. T. TC..С.Т... & 1 & KT596807 \\
\hline
\end{tabular}

Figure 1. Nucleotide polymorphisms of 19 haplotypes observed mtDNA D-loop region in Turkish (TR) and Iranian (IR) chicken sequences. (.) indicate nucleotide positions identical to haplotype Turkish and Iranian chickens, Clade E, haplotype 1 (TRIRE1). Numbers at the top refer to variable sites and correspond to the nucleotide positions of AB114069 (Liu et al., 2006). "N" represents the number of individuals sharing the same haplotypes. 
Table 3. Frequencies of 19 haplotypes in Turkish (TR) and Iranian (IR) chicken populations

\begin{tabular}{|c|c|c|c|c|c|c|c|c|c|c|}
\hline \multirow[b]{2}{*}{ Clades } & \multicolumn{2}{|c|}{ Turkey (TR)* } & \multicolumn{7}{|c|}{$\operatorname{Iran}(\mathrm{IR})^{*}$} & \multirow[b]{2}{*}{$\begin{array}{c}\text { Total } \\
\mathrm{n}=222\end{array}$} \\
\hline & $\begin{array}{c}\text { TRD } \\
\mathrm{n}=31\end{array}$ & $\begin{array}{c}\text { TRG } \\
\mathrm{n}=23\end{array}$ & $\begin{array}{c}\text { IRWM } \\
n=23\end{array}$ & $\begin{array}{l}\text { IRBM } \\
n=30\end{array}$ & $\begin{array}{l}\text { IRNN } \\
\mathrm{n}=22\end{array}$ & $\begin{array}{l}\text { IRCB } \\
n=23\end{array}$ & $\begin{array}{l}\text { IRNH } \\
\mathrm{n}=23\end{array}$ & $\begin{array}{l}\text { IRLR } \\
\mathrm{n}=24\end{array}$ & $\begin{array}{l}\text { IRWA } \\
n=23\end{array}$ & \\
\hline TRIRE1 & 26 & 21 & 19 & 23 & 22 & 20 & 19 & 17 & 14 & 181 \\
\hline TRE2 & 5 & & & & & & & & & 5 \\
\hline TRE3 & & 1 & & & & & & & & 1 \\
\hline TRE4 & & 1 & & & & & & & & 1 \\
\hline IRE5 & & & 3 & 3 & & & & & 1 & 7 \\
\hline IRA & & & 1 & & & 1 & 1 & & & 3 \\
\hline IRE6 & & & & 1 & & & & & & 1 \\
\hline IRE7 & & & & 3 & & & & & & 3 \\
\hline IRE8 & & & & & & 2 & 1 & & & 3 \\
\hline IRE9 & & & & & & & 1 & & & 1 \\
\hline IRE10 & & & & & & & 1 & & & 1 \\
\hline IRE11 & & & & & & & & 4 & & 4 \\
\hline IRE12 & & & & & & & & 1 & & 1 \\
\hline IRE13 & & & & & & & & 1 & & 1 \\
\hline IRE14 & & & & & & & & 1 & & 1 \\
\hline IRE15 & & & & & & & & & 5 & 5 \\
\hline IRE16 & & & & & & & & & 1 & 1 \\
\hline IRE17 & & & & & & & & & 1 & 1 \\
\hline IRE18 & & & & & & & & & 1 & 1 \\
\hline
\end{tabular}

* Abbreviations for breeds are TRD, Denizli; TRG, Gerze; IRWM, White Marandi; IRBM, Black Marandi; IRNN, Naked Neck; IRCB, Common Breed; IRNH, New Hampshire; IRLR, Lari; IRWA, West Azerbaijan.

(181/222). The frequency of TRIRE1 was $87.0 \%$ (47/54) chicken breeds, respectively. The remaining twelve and $79.8 \%(134 / 168)$ in Turkish and Iranian chicken haplotypes (IRE6, IRE7, IRE9-IRE18) were specific to only populations, respectively. Three of 18 haplotypes of clade E one Iranian breed such as IRE11 was found in only IRLR were specific to only Turkish chickens in which one breed.

haplotype (TRE2) was detected in Denizli while 2 haplotypes (TRE3 and TRE4) were only found in Gerze. Fourteen of 18 haplotypes (IRE5-IRE18) in clade E were specific to only Iranian chickens. Two of these 14 haplotypes (IRE5 and IRE8) were shared in three (IRWM,

\section{Within population diversity}

Naked neck breed was found to be monomorphic for the mtDNA region under study while the other eight populations were polymorphic, with the number of IRBM, and IRWA) and two (IRCB and IRNH) Iranian haplotypes (h) ranging from two to six (Table 4). Haplotype

Table 4. Breeds, sampling size (n), number of polymorphic sites (S), number of haplotypes (h), haplotype diversity (Hd), nucleotide diversity $(\pi)$, average number of nucleotide differences $(\mathrm{k})$, and Tajima's D test statistic (D) for each Turkish (TR) and Iranian (IR) chicken populations

\begin{tabular}{lccccccc}
\hline Breeds & $\mathrm{n}$ & $\mathrm{S}$ & $\mathrm{h}$ & $\mathrm{Hd}$ & $\pi$ & $\mathrm{k}$ & $\mathrm{D}$ \\
\hline Denizli (TRD) & 31 & 1 & 2 & 0.279 & 0.0006 & 0.279 & 0.180 \\
Gerze (TRG) & 23 & 3 & 3 & 0.170 & 0.0007 & 0.339 & -1.483 \\
Total & 54 & 3 & 4 & 0.237 & 0.0007 & 0.311 & -1.071 \\
White Marandi (IRWM) & 23 & 10 & 3 & 0.312 & 0.0022 & 1.019 & $-2.102^{*}$ \\
Black Marandi (IRBM) & 30 & 3 & 4 & 0.405 & 0.0013 & 0.637 & -0.374 \\
Naked Neck (IRNN) & 22 & 0 & 1 & 0.000 & - & - & - \\
Common Breed (IRCB) & 23 & 11 & 3 & 0.245 & 0.0022 & 1.027 & $-2.092^{*}$ \\
New Hampshire (IRNH) & 23 & 11 & 5 & 0.324 & 0.0027 & 1.264 & -1.797 \\
Lari (IRLR) & 24 & 5 & 5 & 0.485 & 0.0019 & 0.876 & -1.000 \\
West Azerbaijan (IRWA) & 23 & 11 & 6 & 0.601 & 0.0037 & 1.699 & -1.470 \\
Total & 168 & 22 & 17 & 0.361 & 0.0021 & 0.958 & $-2.078^{*}$ \\
Total & 222 & 24 & 19 & 0.334 & 0.0017 & 0.802 & $-2.178^{* *}$ \\
\hline
\end{tabular}

$* \mathrm{p}<0.05 ; * * \mathrm{p}<0.01$. 
Table 5. Analysis of molecular variance (AMOVA) in Turkish and Iranian chicken populations

\begin{tabular}{lccccc}
\hline \multirow{2}{*}{ Level of analysis } & \multicolumn{3}{c}{ Variance components (\% variation) } & \multirow{2}{*}{$\mathrm{p}$-value } \\
\cline { 2 - 5 } & Within & Among & Total & $\mathrm{F}_{\mathrm{ST}}$ & 0.000 \\
All nine populations & $0.400(95.1)$ & $0.021(4.9)$ & 0.421 & $0.049^{* * *}$ & 0.083 \\
Two Turkish populations & $0.171(96.5)$ & $0.006(3.5)$ & 0.177 & 0.035 & 0.005 \\
Seven Iranian populations & $0.474(96.1)$ & $0.019(3.9)$ & 0.493 & 0.039 & 0.000 \\
Among countries & $0.400(94.4)$ & $0.024(5.6)$ & 0.424 & $0.056^{* * *}$ & 0 \\
\hline$* * * \mathrm{p}<0.001$ & & & &
\end{tabular}

*** $\mathrm{p}<0.001$.

diversity (Hd) varied from 0.00 (Naked Neck) to 0.60 (West Azarbaijan) and was lower in Turkish populations (0.24) compared to Iranian populations (0.36). Hd was 0.33 across all nine populations. Nucleotide diversity $(\pi)$ varied from 0.0000 (Naked Neck) to 0.0037 (West Azarbaijan) and was lower in Turkish populations compared to Iranian populations. Nucleotide diversity was 0.0017 across all nine populations. The mean number of nucleotide differences $(k)$ was low in Turkish populations (0.311) compared to Iranian populations (0.958). The Tajima's D test statistics (D) were statistically significant for only White Marandi and Common Breed populations.

\section{Population structure}

Across all the populations studied, variation among populations was $4.9 \%$ of the total variation while the remaining $95.1 \%$ was due to the diversity within populations (Table 5). Considering only two Turkish populations, variation within populations and among populations was $96.5 \%$ and $3.5 \%$, respectively, of the total variation. Similarly, variation within and among Iranian populations was $96.1 \%$ and $3.9 \%$, respectively.

\section{Network and phylogenetic relationships}

The NJ dendrogram and Median-Joining network for TR and IR chicken populations are shown in Figure 2 and 3, respectively. Clade E was the most frequent haplogroup whereas the clade A consisted of three individuals. Liu's clades B, C, D, F, G, H, and I were not found in Turkish and Iranian chicken populations under study. The major haplotype of clade E was TRIRE1 with the frequency of $81.5 \%$ overall, of which $29.8 \%$ and $51.7 \%$ were observed in the Turkish and Iranian chicken populations, respectively. In clade $\mathrm{E}$, the maximum distances were found between haplotypes of IRE6 and IRE16 with the 12 mutations. The A haplogroup was observed in three populations from Iran (White Marandi, Common Breed, and New Hampshire) and represented by one (IRA) haplotype. The A haplogroup was separated from haplogroup $\mathrm{E}$ by four mutations.

\section{DISCUSSION}

In this study, partial mtDNA D-loop region from 222 chickens from two Turkish and seven Iranian chicken populations were analyzed to clarify their phylogenetic relationship and haplogroups, and to determine mtDNA haplotypes and their maternal ancestry. This is the first report on determining phylogenetic relationship of Turkish and Iranian chickens at the mtDNA level. The neighbourjoining dendrogram results (Figures 2) showed that Turkish and Iranian chickens were not close to red jungle fowl ( $G . g$. gallus, AB007720 and AP003322). Turkish and Iranian

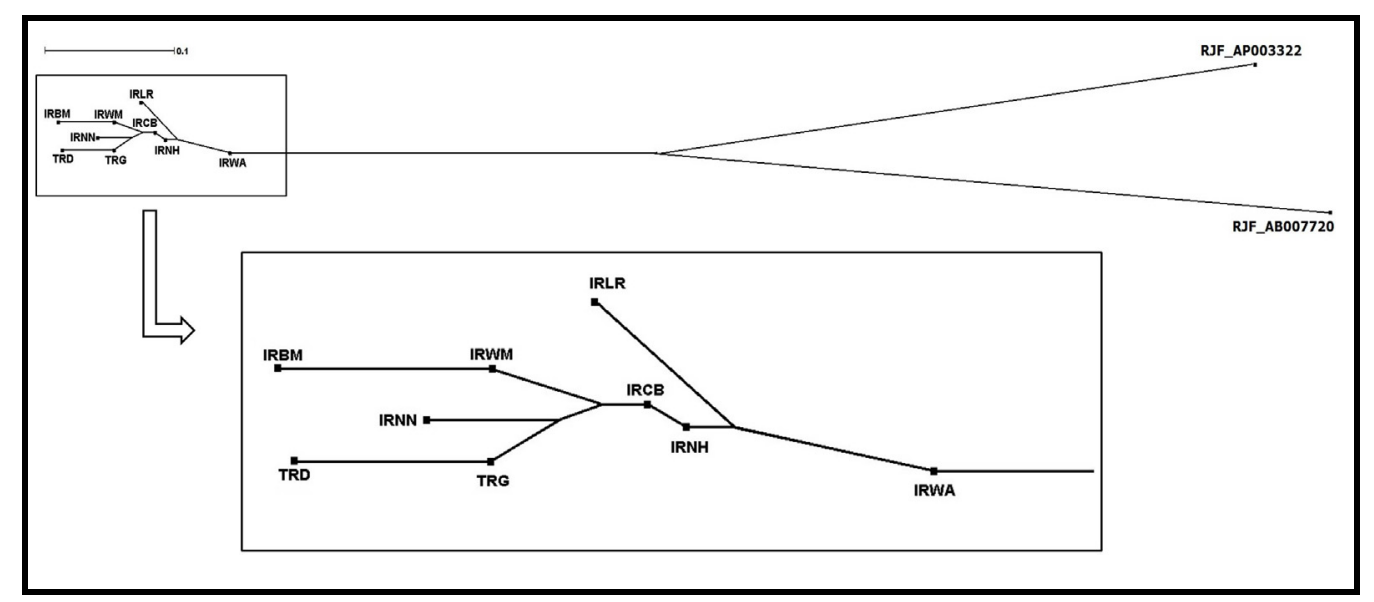

Figure 2. A neighbour-joining (NJ) dendrogram for Turkish (TR) and Iranian (IR) chicken populations. The RJFs (G. g. gallus, AB007720; AP003322) were used as outgroups to root the tree using Splits Tree4 package (TRD, Denizli; TRG, Gerze; IRWM, White Marandi; IRBM, Black Marandi; IRNN, Naked Neck; IRCB, Common Breed; IRNH, New Hemshire; IRLR, Lari; IRWA, West Azerbaijan; RJF, Red Jungle Fowl). 


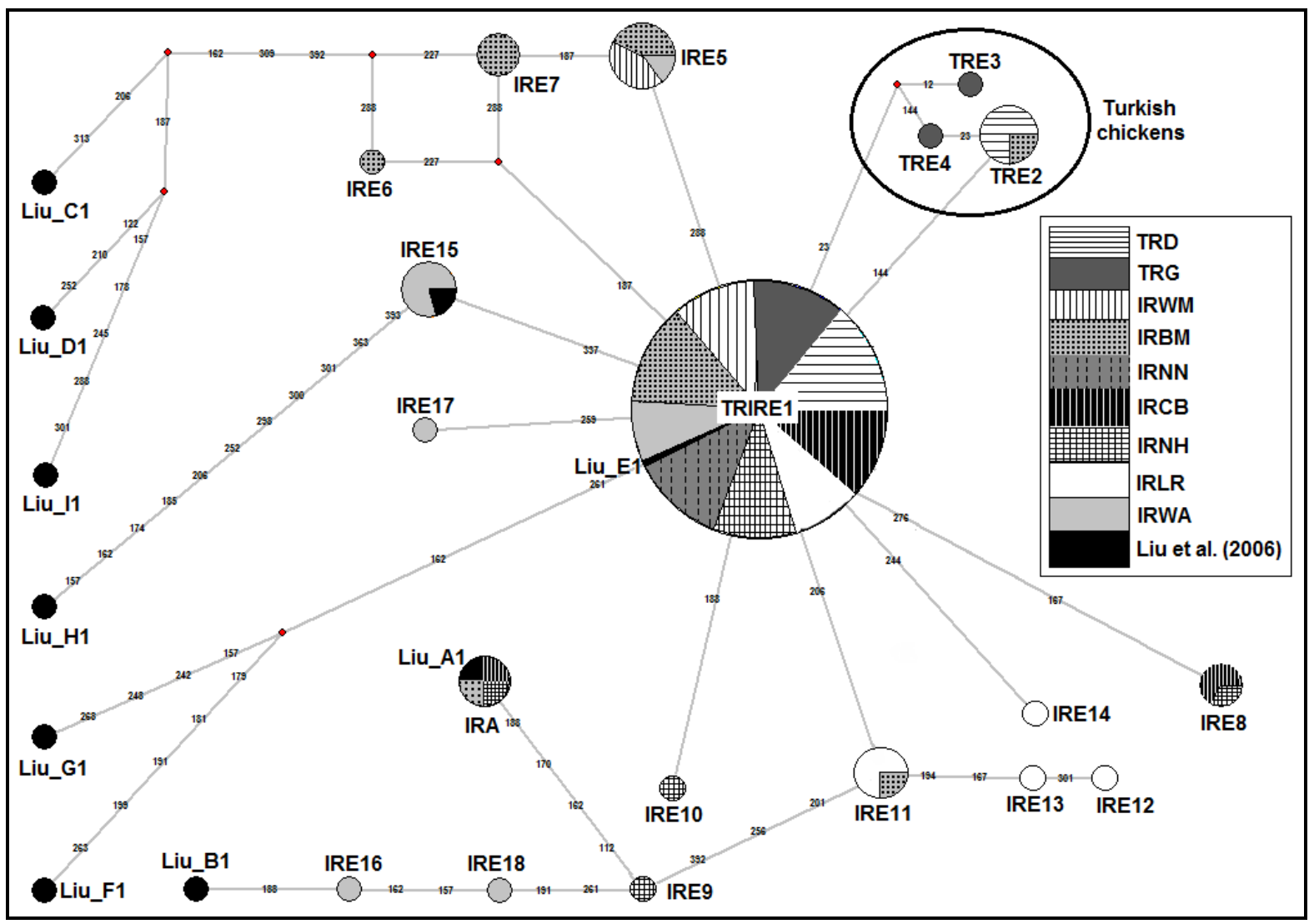

Figure 3. Median-joining network among 19 mtDNA D-loop haplotypes (A, B, and E) observed in Turkish (TR) and Iranian (IR) chicken populations. Data merged with sequences of major haplotypes (Liu_A1-Liu_I1) reported by Liu et al. (2006) as references. The circle areas are proportional to haplotype frequency, and the numbers on the line correspond to mutational positions connecting haplotypes.

chickens shared at high frequency the same cluster (TRIRE1) and may have a common origin.

We revealed existence of two mtDNA D-loop haplogroups, one of which (haplogroup A) were specific to Iranian chickens. Clade E was shared between Turkish and Iranian chickens. The majority of our sequences can be grouped with the haplotype Liu_E1, while one sequence (IRA) can be grouped with reference sequences Liu_A1. Although haplotypes IRE16 and IRE18 are not exactly grouped with reference sequences Liu_B1, both are close to haplogroup B. Haplotypes IRE16 and IRE18 were separated from Liu_B1 by one and three mutations, respectively. Previously, haplogroups A and B were found in South East Asia, China and Japan, respectively (Liu et al., 2006).

Haplogroup A was unique to Iranian chicken population and was not found in Turkish chickens under this study (Table 3). These haplogroups have previously been observed in Yunnan province of China, Japan, Europe and Middle East (Liu et al., 2006), Zimbabwe (Muchadeyi et al., 2008), Madagascar (Razafindraibe et al., 2008), Vietnam (Cuc et al., 2011), and Kenya (Mwacharo et al., 2011). This is the first time that A haplogroup is reported in Iranian
Chickens, but at very low frequencies. The origin of this haplogroup is uncertain. Liu et al. (2006) suggested that haplogroup A and B had a similar geographical distribution and a close phylogenetic relationship. The authors also indicate that both lineages originated from the same ancestral population, Yunnan and/or surrounding regions in China.

All Turkish chickens and high proportion (98.2\%) of Iranian chickens was clustered in clade E (Table 3). This clade has also found in Yunnan province of China, India, Indonesia, Japan, Europe and Middle East (Liu et al., 2006), Hungary (Revay et al., 2010), Vietnam (Cuc et al., 2011), Sudan and Ethiopia (Mwacharo et al., 2011). Liu et al. (2006) showed that clade E included chickens mainly from Europe $(91.38 \%)$, the Middle East (75\%) and India $(55.56 \%)$. The maternal lineages associated with this clade could have originated from the Indian subcontinent (Liu et al., 2006). For that reason, it may be assumed that Turkish and Iranian chickens originated from the most frequent haplogroup in chickens found in many other geographic parts which may have its roots in the Indian subcontinent.

Turkish and Iranian chickens have extensive phenotypic variation in colour, feather types and body size (Düzgüneş 
1990; Shahbazi et al., 2007). Although Turkish and Iranian chicken populations have been previously described as highly polymorphic based on microsatellite markers (Shahbazi et al., 2007; Kaya and Yildiz, 2008), both chicken populations showed low degree of polymorphism in the mtDNA D-loop region and the majority of them were observed in clade $\mathrm{E}$ in this study. In Turkish chickens, the estimated haplotype diversity for Denizli chickens (0.279) was higher than that in Gerze (0.170) (Table 4). According to this result, it can be suggested that Denizli breed is more polymorphic than Gerze breed. Kaya and Yildiz (2008) also reported that the heterozygosity for Denizli chickens $(0.656 \pm 0.045)$ was estimated as higher than that for Gerze chickens $(0.475 \pm 0.074)$ based on microsatellite markers. In Iranian chickens, the higher haplotype diversity (0.601) and nucleotide diversity (0.0037) were observed in West Azarbaijan breed that seems to be more polymorphic in Iran. Shahbazi et al. (2007) also reported that the heterozygosity for West Azarbaijan chickens in Iran were higher than other chickens based on microsatellite markers. Also the estimated haplotype diversity for Turkish chickens was lower than Iranian chickens and those reports in Zimbabwean chickens (Muchadeyi et al., 2008), in East Africa (Mwacharo et al., 2011), and in Vietnamese chickens (Cuc et al., 2011). The nucleotide diversity estimated in this study was similar to that estimated by Liu et al. (2006) for chickens sampled in Europe, Middle East, South East and East Asia and by Revay et al. (2010) for Hungarian indigenous chicken breeds.

Anatolia (Turkey) has been a cradle for civilizations since prehistoric times, because of its geographical location at the intersection of Asia and Europe. Turkish native breeds are thought to be crossbreds of various breeds brought to Turkey from other countries including Iran in different time periods. It is difficult to assess when and how the hybridization has taken shape, because Anatolia (Turkey) has been a passage for a variety of tribes since ancient times (Kaya and Yildiz, 2014). The genetic similarity of Turkish and Iranian chickens found this study may be explained by historical records (Crawford, 1990; 1995) that the chickens may have come through Persia (Iran) to Anatolia (Turkey) and then to Europe during human dispersal and migration. Liu et al. (2006) suggest that despite the gene flow caused by the countless human migrations and trade relations throughout the history, clade $\mathrm{E}$ is in general one of the most widely distributed clades. Most of the European, Indian, and Middle East (including Turkish and Iranian chickens) sequences fall in clade E.

In conclusion, Turkish and Iranian chicken populations showed low degree of polymorphism in the mtDNA D-loop region. Compared to red jungle fowl, Turkish and Iranian chicken breeds are closely related to each other. All Turkish chickens and a high proportion of Iranian chickens were clustered in clade E, which may have originated from the Indian subcontinent. Our results will provide reliable basic information for mtDNA haplotypes of Turkish and Iranian chickens and for studying the origin of domestic chickens.

\section{AUTHOR CONTRIBUTIONS}

HM collected the blood samples, carried out the extraction of genomic DNA, PCR, and DNA sequencing, performed the genetic data analysis and participated in the writing of the manuscript. CPJ collected the blood samples from Iran and helped the extraction of genomic DNA. MAY conceived of the study, participated in its coordination, performed the statistical analysis and participated in the writing of the manuscript. SW participated in writing of the manuscript and interpretation of results. All authors read and approved the final manuscript.

\section{CONFLICT OF INTEREST}

We certify that there is no conflict of interest with any financial organization regarding the material discussed in the manuscript.

\section{ACKNOWLEDGMENTS}

This study was conducted at the Ankara University, Faculty of Agriculture, Animal Sciences, Ankara, Turkey and was partially supported by grants from the The Scientific and Technological Research Council of Turkey (TOVAG-105O446).

\section{REFERENCES}

Besbes, B. 2009. Genotype evaluation and breeding of poultry for performance under sub-optimal village conditions. Worlds Poult. Sci. J. 65:260-271.

Bilgemre, K. 1939. Modern Poultry Husbandry. (1st edn.) Higher Agricultural Institute Press, Ankara, Turkey.

Crawford, R. D. 1990. Origin and history of poultry species. In: Poultry Breeding and Genetics (Ed. R. D. Crawford). Elsevier, Amsterdam, The Netherlands. pp. 1-41.

Crawford, R. D. 1995. Origin, history, and distribution of commercial poultry. In: Poultry Production (Ed. P. Hunton). Elsevier, Amsterdam, The Netherlands. pp. 1-21.

Cuc, N. T. K., H. Simianer, L. F. Groeneveld, and S. Weigend. 2011. Multiple maternal lineages of Vietnamese local chickens inferred by mitochondrial DNA D-loop sequences. Asian Australas. J. Anim. Sci. 24:155-161.

Düzgüneş, O. 1990. Animal genetic resources. In: The Biological Richness of Turkey (Ed. A. Kence). Environmental Problems Foundation Press, Ankara, Turkey.

Eriksson, J., G. Larson, U. Gunnarsson, B. Bed'hom, M. TixierBoichard, L. Strömstedt, D. Wright, A. Jungerius, A. Vereijken, 
E. Randi, P. Jensen, and L. Andersson. 2008. Identification of the yellow skin gene reveals a hybrid origin of the domestic chicken. PLoS Genet. 4:e1000010.

Excoffier, L., G. Laval, and S. Schneider. 2005. Arlequin (version 3.0): An integrated software package for population genetics data analysis. Evol. Bioinform. 1:47-50.

Fumihito, A., T. Miyake, S. Sumi, M. Takada, S. Ohno, and N. Kondo. 1994. One subspecies of the red jungle fowl (Gallus gallus gallus) suffices as the matriarchic ancestor of all domestic breeds. Proc. Natl. Acad. Sci. USA. 91:12505-12509.

Fumihito, A., T. Miyake, M. Takada, R. Shingu, T. Endo, T. Gojobori, N. Kondo, and S. Ohno. 1996. Monophyletic origin and unique dispersal patterns of domestic fowls. Proc. Natl. Acad. Sci. USA. 93:6792-6795.

Huson, D. H. and D. Bryant. 2006. Application of phylogenetic networks in evolutionary studies. Mol. Biol. Evol. 23:254-267.

Kanginakudru, S., M. Metta, R. D. Jakati, and J. Nagaraju. 2008 Genetic evidence from Indian red jungle fowl corroborates multiple domestication of modern day chicken. BMC Evol. Biol. 8:174

Kaya, M. and M. A. Yildiz. 2008. Genetic diversity among Turkish native chickens, Denizli and Gerze, estimated by microsatellite markers. Biochem. Genet. 46:480-491.

Kaya, M. and M. A. Yildiz. 2014. Chicken domestication and indigenous chicken breeds of Turkey. J. Poult. Res. 11:21-28.

Kumar, S., M. Nei, J. Dudley, and K. Tamura. 2008. MEGA: A biologist-centric software for evolutionary analysis of DNA and protein sequences. Brief. Bioinform. 9:299-306.

Librado, P. and J. Rozas. 2009. DnaSP v5: a software for comprehensive analysis of DNA polymorphism data. Bioinformatics 25:1451-1452.

Liu, Y. P., G. S. Wu, Y. G. Yao, Y. W. Miao, G. Luikart, M. Baig, A. Beja-Pereira, Z. L. Ding, M. G. Palanichamy, and Y. P. Zhang. 2006. Multiple maternal origins of chickens: out of Asian jungles. Mol. Phylogenet. Evol. 38:12-19.

Miller, S. A., D. D. Dykes, and H. F. Polesk. 1988. A simple salting out procedure for extracting DNA from human nucleated cells. Nucleic Acids Res. 16:1215.

Mirhosseini, S. Z. and H. Dehghanzadeh. 2003. Study on genetic diversity of Fars native chickens using RAPD markers. In: 3rd National Congress on Biotechnology. Mashhad, Iran. 4:387390.
Muchadeyi, F. C., H. Eding, H. Simianer, C. B. A. Wollny, E. Groeneveld, and S. Weigend. 2008. Mitochondrial DNA Dloop sequences suggest a Southeast Asian and Indian origin of Zimbabwean village chickens. Anim. Genet. 39:615-622.

Mwacharo, J. M., G. Bjørnstad, V. Mobegi, K. Nomura, H. Hanada, T. Amano, H. Jianlin, and O. Hanotte. 2011. Mitochondrial DNA reveals multiple introductions of domestic chickens in East Africa. Mol. Phylogenet. Evol. 58:374-382.

Nishibori, M., T. Shimogiri, T. Hayashi, and H. Yasue. 2005. Molecular evidence for hybridization of species in the genus Gallus except for Gallus varius. Anim. Genet. 36:367-375.

Oka, T., Y. Ino, K. Nomura, S. Kawashima, T. Kuwayama, H. Hanada, T. Amano, M. Takada, N. Takahata, Y. Hayashi, and F. Akishinonomiya. 2007. Analysis of mtDNA sequences shows Japanese native chickens have multiple origins. Anim. Genet. 38:287-293.

Rahimi, G., A. KhanAhmadi, A. Nejati-Javaremi, and S. Esmaeilkhanian. 2002. Estimation of genetic variability in Mazandaran native fowls using RAPD markers. In: Proceedings of 28th International Conference on Animal Genetics. Göttingen, Germany. 120 p. D111.

Razafindraibe, H., V. A. Mobegi, S. C. Ommeh, M. L. Rakotondravao, G. Bjørnstad, O. Hanotte, and H. Jianlin. 2008. Mitochondrial DNA origin of indigenous Malagasy chicken: Implications for a functional polymorphism at the $M x$ gene. Ann. NY Acad. Sci. 1149:77-79.

Revay, T., N. Bodzsar, V. E. Mobegi, O. Hanotte, and A. Hidas. 2010. Origin of Hungarian indigenous chicken breeds inferred from mitochondrial DNA D-loop sequences. Anim. Genet. 41:548-550.

Romanov, M. N. and S. Weigend. 2001. Analysis of genetic relationships between various populations of domestic and jungle fowl using microsatellite markers. Poult. Sci. 80:10571063.

Shahbazi, S., S. Z. Mirhosseini, and M. N. Romanov. 2007. Genetic diversity in five Iranian native chicken populations estimated by microsatellite markers. Biochem. Genet. 45:6375.

Shariatmadari, F. 2000. Poultry production and the industry in Iran. Worlds Poult. Sci. J. 56:55-65.

West, B. and B. X. Zhou. 1989. Did chickens go north? New evidence for domestication. Worlds Poult. Sci. J. 45:205-218. 